\title{
Monitoring and Quantification of Floating Biomass on Tropical Water Bodies
}

\author{
Jan-Peter MUND, Dieter MURACH and André PARPLIES \\ Eberswalde University for Sustainable Development / Germany · jan-peter.mund@hnee.de
}

This contribution was double-blind reviewed as full paper.

\begin{abstract}
Water hyacinth, or Eichhornia crassipes (Mart.) Solms, is an invasive and free floating water plant, native to South America that has often been marked as one of the world's worst invasive aquatic species. It grows into large dense vegetable carpets that block sun energy transmission into shallow waters or even the lake bottom. This study focuses on two different water bodies in the tropical/subtropical zone, where water hyacinth infestation is already an issue.

A parallel research approach was chosen in order to compare regional results with regards to operability and suitability of the chosen method. The first area studied is the southeastern area of the Inle Lake in Central Myanmar, and the second region is the Winam Gulf on Lake Victoria in Kenya. The Winam Gulf has been clogged by Eichhornia crassipes for decades, in contrast to a few reports about Water hyacinth infestation on the Inle lake waters. As in many other countries in the tropics, the current local monitoring and control measures of invasive aquatic vegetation in Myanmar and Kenya mostly rely on simple observations and mechanical methods. The monitoring and quantification of spatialtemporal variation of floating vegetation using satellite images has been tested in many approaches as being useful for analysing the spatial extent and temporal abundance of the macrophytes on tropical water bodies (SCHOUTEN 1999 et al., ALBRIGHT 2004 et al., NASA 2007, LANEVE 2010 et al., WINSTANLEY 2011 et al. ).

The objective of the presented study was to test a multi-sensor approach, combining several remote sensing methods at two different locations, with particular ecological and land use systems, in order to detect and monitor floating biomass, and assess the abundance and quantity of Eichhornia crassipes and similar floating macrophytes using MERIS, MODIS and Landsat 7-ETM imagery. The successful multi sensor approach resulted in temporal spatial patterns of floating biomass, enabling transformable quantifications for the detected floating biomass. The quantified and harvestable biomass can be used further as a permanent source of bioenergy, or a resource for a chemical process named Hydrothermal Carbonization (HTC), converting biomass into an alternative energy source (hydrochar) or into solid or liquid fertilizer (LIBRA et al. 2011).
\end{abstract}




\section{Introduction}

Water hyacinth, or Eichhornia crassipes (Mart.) Solms, is an invasive and free floating water plant native to South America. Water hyacinth has often been marked as one of the world's worst invasive aquatic species. In the course of the last century it has infested many tropical water bodies all over the globe. It grows into large dense vegetable mats which block the sun energy transmission into shallow waters, or even the lake bottom. These mats or thick carpets quickly change their position depending on the currents or regional dominating wind vectors. The combustion of floating plants results in a severe threat to the native ecosystems and biodiversity, to local irrigation systems, and dams. It affects the livelihood of local people by blocking and clogging water bodies, dams, irrigation canals and harbours. Such effects are challenging the lifestyles of the local inhabitants (CAVALLI et al. 2009). Furthermore, water hyacinth tolerates either very high amounts of nutrients or very low amounts, such as nitrogen and phosphorus. At the same time it does not occur in water bodies with salinity rates greater than $15 \%$ (JONES 2009). The reproduction rate and growth correlates with the amount of available nutrients in the habitat (Romero et al. 2005). The current local monitoring and control measures of invasive aquatic vegetation mostly rely on biological, chemical and mechanical methods (WINSTANLEY et al. 2011).

In the African TIGER Initiative several research teams (Cavalli et al. 2009; Laneve et al. 2010) tested and compared the sensitivity of several multi- and hyperspectral sensor types like CHIRS and MERIS. Their studies proved that only the integration or satellite image fusion techniques of at least two different spatial and spectral sensors with medium to high spatial resolution allows the discrimination of different species composing floating vegetation like Water Hyacinth, Nile Cabbage, Water Lylium in the Winam Gulf.

The objective of the presented study is to test if long time series of medium to high resolution satellite imagery and image fusion technology, in combination with standard methods for biomass detection, can support setting up monitoring systems for weed infested tropical water bodies. A parallel research approach was chosen in order to compare regional results in regard to operability and suitability of the chosen method. This study focused on the following five subjects:

- Testing various image interpretation methods and indices detecting floating vegetation carpets of macrophytes

- Detection and estimation of temporal abundance of Eichhornia crassipes carpets on medium to high resolution imagery

- Temporal quantification of the total water area covered by dense vegetable mats

- Spatial location of temporal vegetable covers and identification of spatial density

- Assessment and quantification of potential harvestable biomass

The successful remote sensing approach resulted in various temporal and spatial patterns of floating biomass and comparable quantifications for the floating biomass. The located and harvestable biomass can be used as a permanent resource for bioenergy, or for a chemical process named Hydrothermal Carbonization (HTC), which converts biomass into an alternative energy source called hydrochar or into fertilizer (LIBRA et al. 2011). 


\section{Study Area}

This study focuses on two different water bodies in the tropical/subtropical zone, where water hyacinth infestation is already an issue. The first study area is located the southeastern area of the Inle Lake. Lake Inle is the second largest lake in Myanmar with an estimated surface area of approx. 1,16 Mio ha, where Eichhornia crassipes is abundant (Fig. 1 and 3). The lake is known for its unique floating garden agriculture and villages on stilts, while other parts of the lake are covered by reeds, floating plants (Fig. 3). This specific lake structure and the floating gardens might hamper the correct classification of floating vegetation and water hyacinth on medium scale imagery.

The second region is the Winam Gulf (approx. 16 Mio ha) of Lake Victoria in Kenya. Winam Gulf has been clogged by Eichhornia crassipes for decades (Fig. 2 and 4). The gulf is a NE inlet of the world's second largest inland water body known for its abundance of aquatic wildlife. The gulf provides a major contribution to the local economy, supporting an estimated population of over 20 million (LANEVE et al. 2010). A study from ALBRIGHT et al. (2001) concluded that Winam Gulf was the most heavily infested part of the northern region of Lake Victoria from 1994 till 2001.

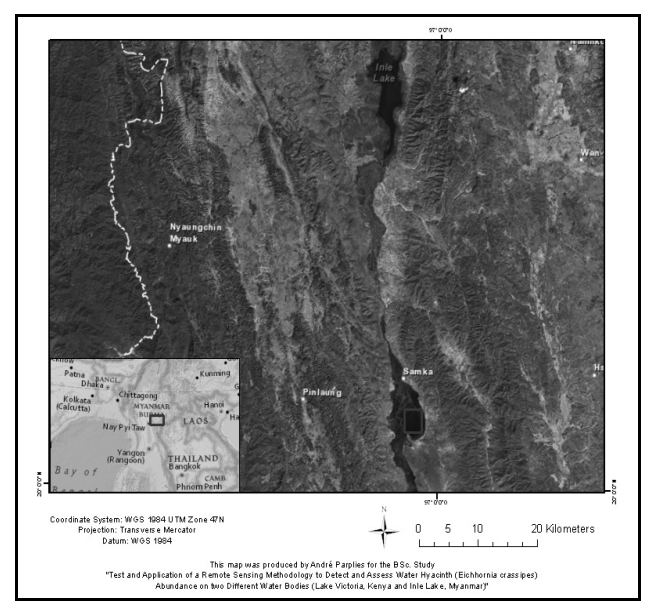

Fig. 1: Overview map, Inle Lake, Myanmar

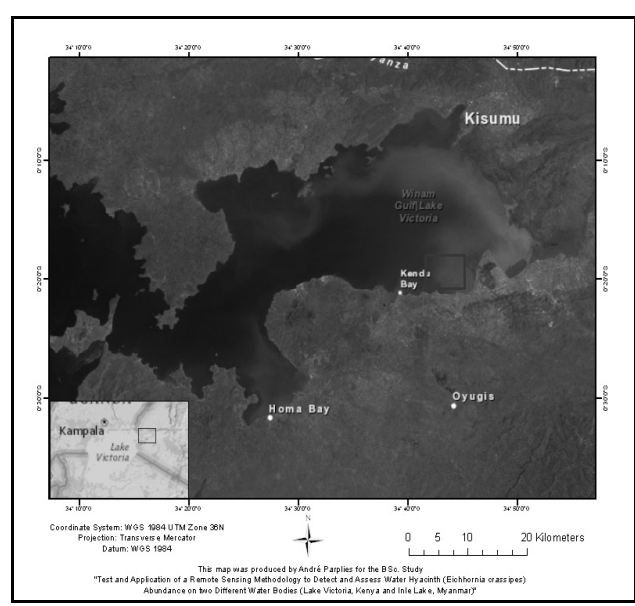

Fig. 2: Overview map, Winam Gulf, Lake Victoria, Kenya

\section{Data Used}

In the presented study only freely available Landsat ETM 7 imagery and MODIS, MERIS data from the last decade (2000 to 2011) were used in order to detect and assess the abundance of Eichhornia crassipes and similar floating macrophytes on two tropical water bodies in East Africa and South-East Asia (Tab. 1).

A preliminary query of several Landsat archives resulted in only a small number of mostly cloud free available TM and ETM data. This amount of data was considered insufficient for analysing intra seasonal time series of floating vegetation. Therefore longer time series of 
decadal or monthly MODIS and MERIS image stacks have been used in addition to Landsat time series to monitor the extent of the floating vegetation.

The utilization of the $250 \mathrm{~m}$ spatial resolution channels of MODIS have been discussed by LANEVA et al. (2010) posing concerns regarding the capability to detect floating vegetation and to distinguish water hyacinth from other floating weeds of the lake.

Tab. 1: Remote sensing data selection

\begin{tabular}{|l|l|l|l|l|l|}
\hline Sensor & $\begin{array}{l}\text { Spatial } \\
\text { resolution }\end{array}$ & $\begin{array}{l}\text { Spectral resolution } \\
\text { (Visible and NIR) }\end{array}$ & $\begin{array}{l}\text { Swath } \\
\text { width }\end{array}$ & $\begin{array}{l}\text { Temporal } \\
\text { resolution }\end{array}$ & Years \\
\hline MERIS & $300 \mathrm{~m}$ & 15 bands & $1150 \mathrm{~km}$ & 3 days & $2003-2011$ \\
\hline MODIS & $250 \mathrm{~m}$ & 4 bands & $2330 \mathrm{~km}$ & 16 days & $2001-2011$ \\
\hline Landsat-7 & $30 \mathrm{~m}$ & 6 bands & $185 \mathrm{~km}$ & 16 days & $2000-2011$ \\
\hline
\end{tabular}

However, water hyacinth and similar floating vegetation tend to concentrate in larger mats, often exceeding several $100 \mathrm{~m}^{2}$ (SCHOUTEN et al. 1999). These larger vegetable carpets are easily detectable even on medium resolution imagery like MODIS and MERIS. The combination of MODIS and MERIS imagery was used to perform change detections in vegetation and to identify the dispersion of floating vegetation throughout time. Furthermore, a data fusion of MERIS and ETM-7 data was used to discriminate different types of floating vegetation, as already suggested by LANEVA et al. in 2010 .

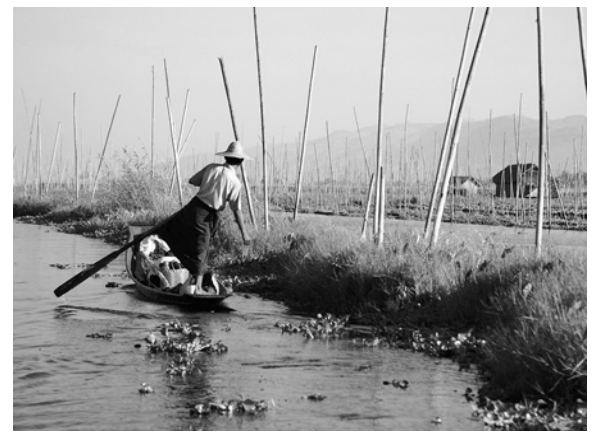

Fig. 3: Floating garden with Water Hyacinth at Inle lake 2010 (photo T. Schoch)

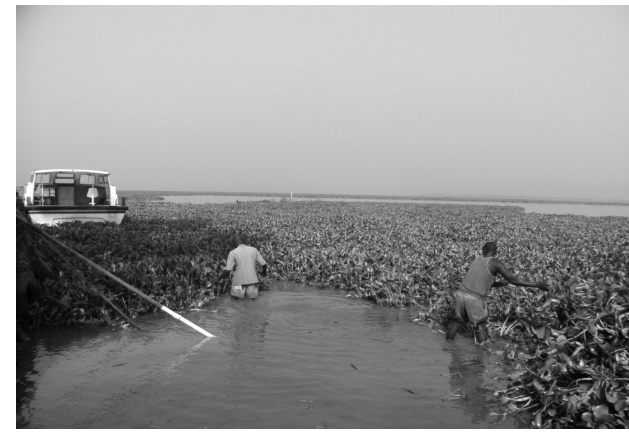

Fig. 4: Water Hyacinth infestation in the Winam Gulf, Lake Victoria, Kenya

\section{Methodology}

Several remote sensing index methods for detecting vegetation cover and floating biomass like NDVI and SAVI or MSAVI can be applied to detect any vegetation, including aquatic vegetation. Jung Cho et al. (2008) proved in their study that the "Normalized Difference Vegetation Index" (NDVI) can be used reliably to detect aquatic vegetation on water surfaces until a depth of approximately 0.3 meters, where measurements become inaccurate with increasing water depth. Accordingly, in the first step of our study, the NDVI calculation was conducted separately on both image scales (MERIS and Landsat), as described in 
detail in the next paragraph. Successively the NDVI results from individual scenes and both image scales were fused to a merged NDVI result on the Landsat data scale. The image preprocessing, image analysis and post classification was carried out using ERDAS 11 and R statistic and image analysis suite.

To reduce the study area to an adequate image size for better processing and testing using the data fusion algorithm and image analysis procedures, certain areas of interest (AOIs) were clipped from the full image scenes. To assure that the clipped areas are situated exclusively on water and contain no land surface, the coastline was visually identified using different band combinations on ETM 7 in order to produce a water mask. Producing a reliable water mask is considered a challenging issue (CHERUIYOT et al. 2013), especially when dealing with water bodies characterized by a high frequency and amplitude of changing water levels (e.g. Inle Lake). Further details regarding the characteristics of the vegetation floating on the lakes and the state of the lake water (water colour, suspension, soluble matter) were obtained by exploiting the MERIS and Landsat ETM 7 images. A specific image analysis workflow to assess the spatial extent of aquatic vegetation on the lakes was created and tested in a semi-automated prototype. The suggested workflow consists of four individual sections:

1. Image preprocessing tasks and multisensory image fusion including radiometric and geometric correction and SLC-off gap filling methods (SCARAMUZZA et al. 2004)

2. Selection of the area of interest, water masking including coastline delineation, extraction of spectral signature files including measuring spectral reflectance of Eichhornia crassipes using terrestrial spectroscopy (CHERUIYOT 2013)

3. Image analysis, detection and unsupervised classification, NDVI thresholding, and supervised classification (Max. Like.) of floating biomass, including NDVI, supervised thresholding and post classification methods

4. Accuracy assessment and biomass quantification.

Based on the spectral unmixing of field data from spectrometers and intermediate results from ETM-7 and MERIS time series it can be assumed that water hyacinth and other floating vegetation provide a significant band ratio of ETM bands 3;4;5 (Fig. 5 and 6). A signature file containing the unique reflectance values of water hyacinth has been created successfully with plausible results.

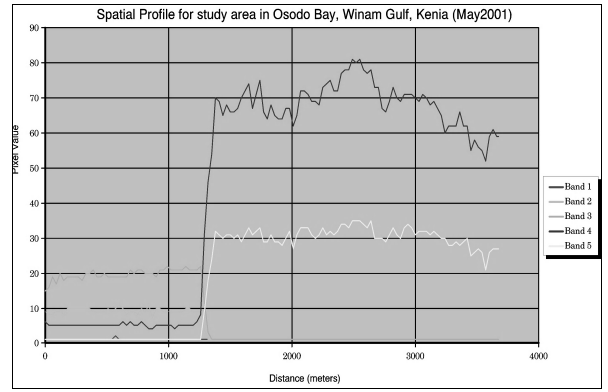

Fig. 5: Spatial spectral profile along a transect of open water and expected water hyacinth in Osodo Bay, Kenya

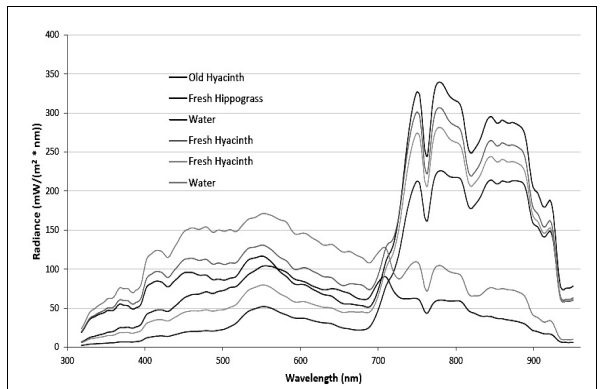

Fig. 6: Field spectral measurements of Eichhornia crassipes (courtesy of CHERUIYOT et al. 2013) 
The extracted spectral signature files in combination with MERIS and ETM-7 NDVI means were used to classify all AOI image data into four separate classes of sparse and dense floating vegetation, open water, and any other reflectance. Separation of floating vegetation from submerged/sparse vegetation and water, and the determination of dense and light water floating vegetation, was performed using the decadal NDVI image from MODIS data as a reference. NDVI values close or slightly above zero in marginal areas of supposed water hyacinth infestations were taken as training data for the "Water hyacinth (light)" class. Pixels are classified applying individual threshold values that can be adjusted manually in the process by the image interpreter.

In a final processing step, the discriminated spatial extent of water hyacinth and other floating vegetation are quantified and recalculated into dry matter biomass. In 2005, the annual dry matter biomass $[\mathrm{DM}]$ yield of water hyacinth per hectare was estimated in an empirical study by Aboud et al. summing up to approx. 30.45 tons [DM/ha/year] at $9 \%-10 \%$ DM content. This estimate follows a conservative approach and calculates a substantially lower amount than most other estimates in literature (ABOUD et al. 2005).

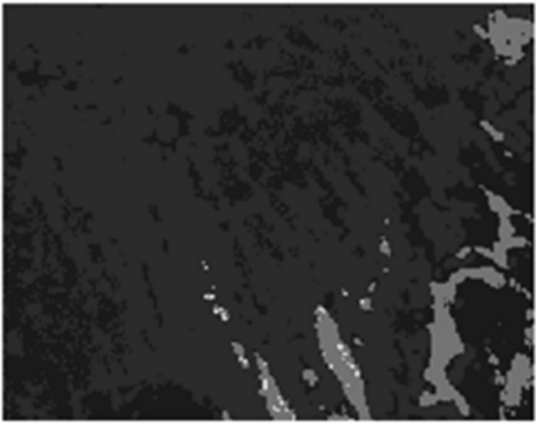

Image after Thresholding

Fig. 7: Landsat ETM-7 2001; Thresholding of classified NDVI Data; Inle Lake

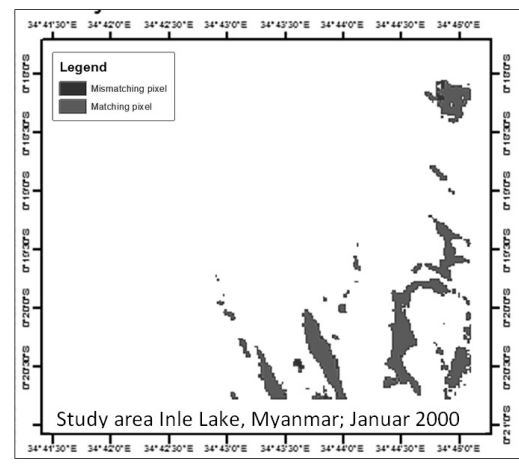

Fig. 9: Results of accuracy assessment at Inle Lake, Myanmar based on data fusion of ETM-7 and MERIS Data

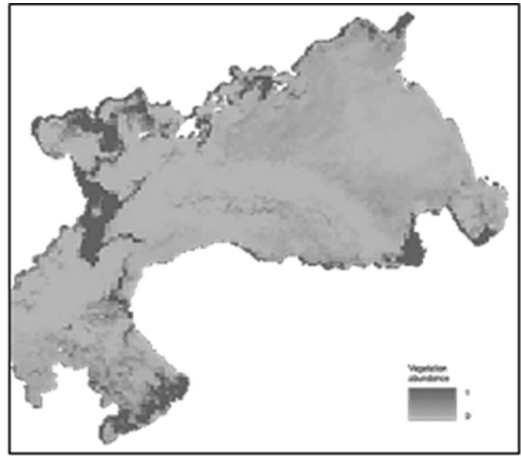

Fig. 8: Long term vegetation cover on Winam Gulf, Kenya based on ETM and MERIS

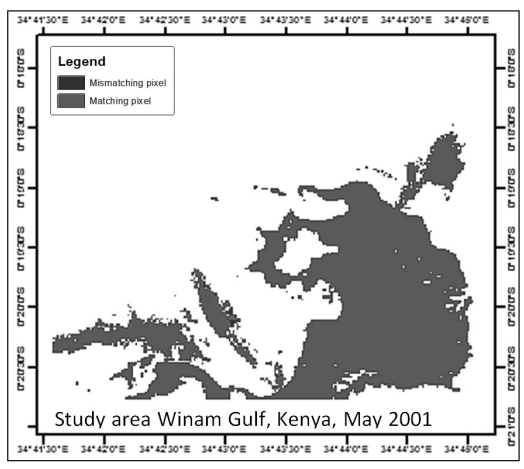

Fig. 10: Results of accuracy assessment at Winam Gulf, Kenya based on data fusion of ETM - 7 and MERIS Data 


\section{Results and Discussion}

A NDVI based and supervised classification algorithm was applied to ETM imagery; MODIS and MERIS imagery were classified using an NDVI based unsupervised classification algorithm. This semi-automated classification segmentation process applied to Landsat ETM 7 and MODIS/MERIS imagery allowed the classification of floating macrophytes with the aim of highlighting the spectral extent of floating vegetation over 11 years until 2011. Figures 7-10 provide intermediate results of the NDVI calculation with thresholding, the classification algorithm, and the accuracy assessment process. The semi-automated image fusion and classification approach produces several tables of signature values which have been reclassified into four different surface classes:

- $\quad$ sparse (light) floating vegetation (combination of submerged and floating species);

- dense floating vegetation (most probably mats of Eichornia crassipes);

- open water;

- $\quad$ other - non-classified pixels.

Overall, the classification accuracy for all four classes ranged from $72 \%$ to $81 \%$ for both long term time series. To enhance the validation and evaluation procedure of the results it would be necessary to access detailed ground data and reliable information about the seasonality and spatial density of floating vegetation, in order to assess the available biomass. ALBRIGHT et al. (2001) stated in their study that they found little reliable reference data about spatial and temporal water hyacinth abundance.

The tables shown in Fig. 11 and 12 provide a spatio-temporal analysis of the periodicity of floating vegetation in both test areas. In general, the sparse floating vegetation covered a greater area on both lakes during the 11 year observation period. This result can be interpreted as a negative outcome of the image fusion algorithm and the spatial inaccuracy of medium scale MODIS and MERIS imagery. The discrimination of sparse and dense floating vegetation is possible only on a combination of MERIS and ETM-7 data, but not on a combination of MODIS or ETM7 imagery.

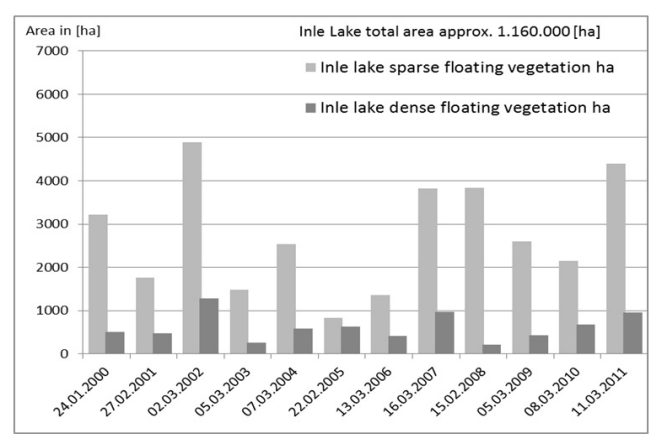

Fig. 11: Area of floating biomass on the Inle Lake, Myanmar $2000-2011$

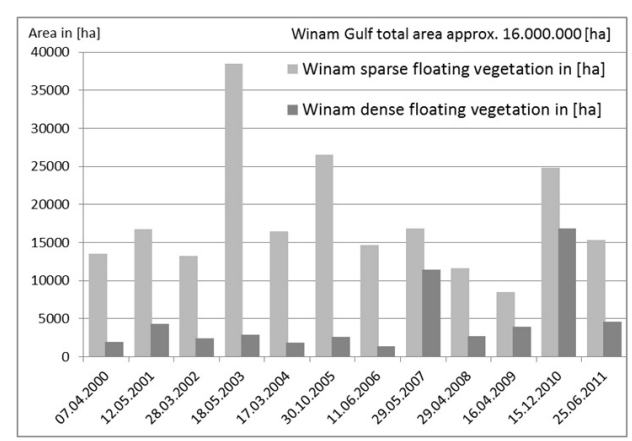

Fig. 12: Area of floating biomass at the Winam Gulf, Kenya $2000-2011$ 
From 2000 to 2011 the spatial extent of sparse floating biomass fluctuated on both lakes within a range of more 3000 ha on the Inle Lake and more than 35000 ha in the Winam Gulf, without any significant trend. On the Inle Lake, the classification results show four peaks in 2000, 2002 2007-08 and 2011, which show a high frequency or periodicity and no significant correlation to the variability of dense floating vegetation. In the Winam Gulf, there were only three peaks of sparse floating vegetation in 2003, 2005 and 2010 measured in comparison to FUSILLI et al. (2011).

The spatial extent of dense floating vegetation on the Inle Lake ranges between 250 ha and 1300 ha, showing large scale variations without a trend and only one peak in 2002. The dense floating vegetation in the Winam Gulf ranges from 1300 ha in 2006 to 11000 ha in 2007 with two peaks, and 16000 ha in 2010. The lack of intra-seasonal image collection available for this study limits the probability to identify any seasonal periodicity of water hyacinth abundance in the gulf.

To contribute to the suggested Hydrochar project, which aims to turn water hyacinth biomass into an energy source and fertilizer through the HTC process, it is imperative to quantify the areas occupied by water hyacinth. The calculated average amount of dense floating vegetation in both research areas, which is most probably Eichhornia crassies, at least in the Winam Gulf, has been estimated to an amount of 145.000 t/DM/y (Winam Gulf), and approximately $18.000 \mathrm{t} / \mathrm{DM} / \mathrm{y}$ on the Inle Lake in Myanmar. The calculated results of annual dry matter biomass based on empirical DM biomass quantifications from literature show a very high inter annual variability and a similarly high seasonality, which has not been subject of this study. Results from the Inle Lake research area need to be further verified based on high to very high resolution imagery, or texture and structure based image segmentation and object identification classification processes, due to adverse classification effects of the abundance of floating garden vegetation along the lake shores.

\section{Conclusion}

The monitoring processes and quantification results of the spatial temporal variation of floating vegetation, obtained by analysing time series of satellite images, has been tested in many approaches as being useful for the analysis of the macrophytes on tropical water bodies (SCHOUTEN 1999 et al., ALBRIGHT 2004 et al., NASA 2007; LANEVE 2010 et al., WINSTANLEY 2011 et al.).

The presented semi-automatic, long term, remote sensing NDVI-based monitoring and quantification process proves the efficiency of using a combination of medium to high resolution satellite imagery from MODIS, MERIS and Landsat, in order to locate and quantify the spatial distribution of the floating vegetation on a water surface. The presented results show that the tested image fusion and classification method is appropriate to detect water hyacinth abundance and other sparse floating vegetation on topical open water bodies using freely available multi- to hyper spectral satellite imagery. This approach is capable of producing reliable quantifications of a minimum to average amount of dry matter biomass per year, even though the observed and classified coverage of floating vegetation varies over a period of 11 years 
The selection of only one acquisition date per year is reliable enough to test the suggested monitoring method even though a higher density would improve the detection of the spatial location and inter-seasonal variation of floating vegetation. The number of available images, especially ETM 7 per year, was limited, mostly due to higher cloud cover. The MERIS Sensor with its higher spectral resolution allows the discrimination of two floating vegetation classes, and the data fusion of Landsat ETM 7 and MERIS provides a more detailed spatial extent of the phenomena of floating vegetation. Only the high revisit frequency of the MODIS scanner allows adequate time series for the analysis of the seasonal periodicity, but with certain limits to spatial and spectral resolution. Several ecological and statistical uncertainties and misclassification could be reduced by taking a high number of images per year into consideration.

Another crucial outcome of comparing the results from this methodological approach in two different regions is that the chosen image fusion method of MERIS data with Landsat data does not meet the spatial accuracy and pixel scales required to assess and quantify floating vegetation in the divers Lake Inle aquatic environment.

\section{References}

Aboud, A. A. O., Kidunda, R. S. \& Osarya, J. (2005), Potential of water hyacinth (Eichornia crassipes) in ruminant nutrition in Tanzania. Livestock Research for Rural Development, 17. http://www.lrrd.org/lrrd17/8/abou17096.htm (02.02. 2014).

Albright, T., Moorhouse, T. \& MCNABB, T. (2004), The abundance and distribution of water Hyacinth in Lake Victoria and the Kagera River Basin, 1989-2001. Journal of Aquatic Plant Management, 42 (2), 73-84.

Cavalli, R. M., Laneve, G., Fusilli, L., Pignatti, S. \& Santini, F. (2009), Remote sensing water observation for supporting Lake Victoria weed management. Journ. of Environm. Man., 90 (7), 2199-2211.

Cheruiyot, E., Menenti, M., Gorte, B. \& Mito, C. (2013), Remote sensing observation of aquatic plants proliferation. In: Presentation and Discussion paper at Living Planet Symposium 2013.

Fusilli, L., Collins, M. O., Laneve, G., Palombo, A., Pignatti, S. \& Santini, F. (2011), Assessment of the abnormal growth of floating macrophytes in Winam Gulf (Kenya) by using MODIS imagery time series. International Journal of Applied Earth Observation and Geoinformation. www.researchgate.net/...abnormal.../79e4150bf712b61a3f.pdf (02.04. 2014).

JONES, R. W. (2009), The impact on biodiversity, and integrated control, of water hyacinth, Eichhornia crassipes (Martius) Solms-Laubach (Pontederiaceae) on the Lake Nsezi Nseleni River System. http://eprints.ru.ac.za/1600/2/Jones-MSc-TR09-11.pdf (06.06.2012).

Jung Cho, H., Kirui, P. \& NATARAJAN, H. (2008), Test of multi-spectral vegetation index for floating and canopy-forming submerged vegetation. www.mdpi.com/1660-4601/5/5/477/pdf (29.05.2012).

Laneve, G., Cavalli, R.M., Fusilli, L., Palombo, A., Pignatti, S. \& Santini, F. (2010), Development of an operational system for monitoring and predicting the aquatic plants proliferation in the Lake Victoria. In: ESA TIGER Workshop papers 2010. 
Libra, J. A., Ro, K. S., Kammann, C., Funke, A., Berge, N. D., Neubauer, Y., Titirici, M.-M., FÜHNER, C., BENS, O., KERN, J., EMMERICH, K.-H. (2011), Hydrothermal carbonization of biomass residuals: a comparative review of the chemistry, processes and applications of wet and dry pyrolysis. In: Biofuels, 2 (1), 89-124.

NASA EARTH OBSERVATORY (2007), Water Hyacinth Re-invades Lake Victoria. http://earthobservatory.nasa.gov/IOTD/view.php?id=7426 (01.10.2012).

Romero, J. R., Alexander, R., Antenucci, J. P., Attwater, G., Ewing, T., Feaver, S., Imberger, J., Khisa, P., LAM, C., Nuuguna, H. \& Shimizu, K. (2005), Management implications of the physical limnological studies of Rusinga Channel and Winam Gulf in Lake Victoria. ILEC. In: Proc. 11th World Lake Conference, Nairobi.

Scaramuzza, P. \& MiciJevic, E. (2004), SLC Gap-Filled Products Phase One Methodology. http://landsat.usgs.gov/documents/SLC_Gap_Fill_Methodology.pdf (28.01.2014).

Schouten, L. S. M., VAN LeEUwen, M. H. J. C., BAKKER, J. G. M. \& TwONG; T. (1999), Water Hyacinth Detection in Lake Victoria by means of Satellite SAR. In: USP-2; Report 98-28.

Winstanley, H., Jeyaprakash, T., Martins, M., Aligeti, N. \& Stodghill, J. (2011), Mapping Aquatic Vegetation on Lake Victoria. In: Earthzine, posted on August 10th, 2011. Earthzine, Develop Virtual Poster Session.

http://www.earthzine.org/2011/08/10/mapping-aquatic-vegetation-on-lake-victoria/ (21.01.2014). 